C.I.F. T. XI, Fasc. 1 y 2 (1985), págs. 59-69

\title{
EL DECALOGO CIEGO Y LOS YOHOOS
}

\author{
Luis Martínez de Mingo* \\ I.N.B. de Alcobendas (Madrid)
}

\section{RESUMEN}

Apoyado en ciertas concepciones borgianas de la literatura: "somos perpetuamente moralistas y sólo a veces geómetras", la ironía y el juego, el autor del artículo propone una alteración del orden de los relatos de El Informe de Brodie (1970) que es, a la vez, malévola y poética.

Todos los libros están en uno solo-Borges dixit-y ése puede ser la anti-Biblia (la culpa, la historia, la guerra, el dehonor, etc.) incluso en El Informe. Ahora bien, el libro de Borges contiene también una petición, y justamente al final: si somos tanto más cultos cuanto más respetemos lo diferente, los Yahoos deben ser salvados puesto que, entre otras muchas cualidades, tienen la facultad de previsión y "su infinito empieza en el pulgar". Imponerles nuestras creencias sería fagocitarlos pero, desgraciadamente, es muy posible que la petición que un humilde servidor se atreve a hacer a Su Majestad sea arrojada a la papelera por el primer ujier de la mañana. Es un decir.

\section{ABSTRACT}

Based on certain Borgean understanding of literature ("we are moralists forever, and only sometimes geometricians"), irony and game, the author proposes a both malevolent and poetical change in the sequence of the stories of El Informe de Brodie (1970).

Books are all in just one-Borges dixit-, which may be the anti-Bible (guiltiness, history, war, dishonor, etc.), or even El Informe. However, Borges' book also has a request, and it's just at the end: if the more educated we are, the more respectfull we are of the different, then the Yahoos must be saved, because, besides many other qualities, they have the foreseeing ability, and "their infinite begins on the thumb". Imposing our beliefs on them would be ingesting and destroying them; but, unfortunately, the request your humble servant dares to address Your Majesty, may be thrown to the waste paper bin by the earliest rising usher. It's a manner of speaking.

* Licenciado en Filología Hispánica. Dpto. de Literatura; I.N.B. "Giner de los Ríos"; Alcobendas (Madrid). Recibido el 10-7-1986. 


\section{De cómo David Brodie (que no Bowie) entendió la cultura}

Como no voy a pretender la ingenuidad de intentar un texto sin referencias, evitaré, a ser posible, lo que Eco llama "la literatura intencionada", es decir, el pastiche mimético. Rehuiré lo fácil cuando pueda, no ahora que tengo que decir la primera obviedad: El Universo es todos los libros y somorgujo- no hay en la tierra una sola página, una sola palabra sencilla, ya que todas postulan el Universo, cuyo más notorio atributo es la complejidad -Brodie dixit-.

En todo caso la sintaxis siempre será un refugio de orden ante el caos amenazante. El Silencio Elocuente que emanaba de la música de las Esferas, obligó a Pitágoras a ordenar un Sistema que, desde luego, fue posterior al miedo. El mismo miedo a la vida irracional y absurda es el que ha hecho de J.L.B. el funcionario de la Biblioteca Nacional, el hombre pertrechado en citas, inamovible en ese orden infinito de las paginaciones y, al cabo, desnudo, enamorado de Hamlet y Durero: "El Caballero y la muerte". Todos esos libros están en uno y ése puede ser El informe de Brodie. Si el mismo J.L.B. no ha tenido más remedio que terminar siendo Borges, es decir una monotonía, una tauto-logía, en cualquier libro se filtran todos sus temas porque uno, a sí mismo, se sabe de memoria y más si se lleva tan bien aprehendido, por eso la poesía estaría siempre en la nostalgia, en la añoranza o en el deseo. A nadie se le ocurre decir "Poesía soy yo", ¿verdad tú?.

Lo que sí haré será variar el orden de colocación de los relatos para proponer otro, malévolo como todos, y embaucador pero que ahora puede servir si de dar un informe del Informe se trata.

La propuesta es que J.L.B., a través de ese sueño dirigido que es la literatura, va a hacer, en este libro, un repaso a toda la Historia de la Humanidad a través de los temas subyacentes a las Civilizaciones. El hombre raramente escapa del terreno de la Moral, en sus repetidos hábitos se desvelan, uno y otro día "at twelve o'clock", los mismos límites bajo distintos meridianos: la culpa, los duelos, el engaño, el amor. "La prudencia y la justicia son preeminencias y virtudes que corresponden a todas las épocas y a todos los lugares; somos perpetuamente moralistas y sólo a veces geómetras" ${ }^{2}$. Borges, con una actitud terriblemente realista ("la poesía es economía pura, se escribe para entender el mundo"), impacable y descreída, reescribe otra Biblioteca a base de casos simbólicos. En el Informe cabe toda la tragicómica provisión de aconteceres pero, paradójicamente, no tiene lugar el amor, al menos como motor del mundo, y sí toda la suerte de infamias, violencias y engaños que constantemente nos motivan. Si el mundo no es así,

Nota.- David Bowie es un famosísimo actor y cantante actual.

1. Todas las citas de textos de Borges pertenecen a Prosa Completa, Ed. del Círculo de Lectores, Barcelona, 1975.

2. Prólogo al Elogio de la sombra. J.L. Borges, en ed. cit. supra, pág. 654. 
al menos desde esa visión de profeta de un Olimpo vacío, que es capaz de decir: "Mon siège est fait"3 , es explicable. Desde allí se deben ver así las cosas, muchas veces desde aquí también, mas lo que difícilmente olvidaré es una frase que a J.C. Onetti le oí decir sobre el autor del Informe. No negándole su gran calidad, decía el autor de Juntacadáveres, que lo que raramente pudo ocultar Borges es la desazón del que nunca ha sido feliz, y, desde luego su vida no se nos antoja un lecho de rosas. Su incondicional amiga $\mathbf{M}^{\mathrm{a}}$. Esther Vázquez cuenta, en un libro precioso -Monte Avila, editor ${ }^{4}$, que Borges ha sido acompañado por variadas y tenues presencias femeninas pero todavía no ha hallado la mano en que apoyarse y ha sufrido su soledad. Quizás la gran lección de este libro sea esa frase que se dice en algún sitio del mismo: "Quien sea capaz de amar respetando la libertad del

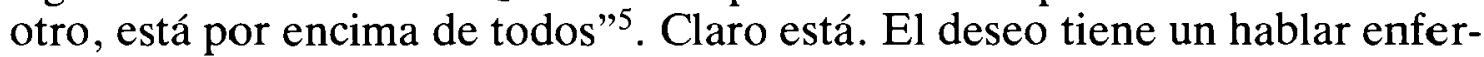
mo, porque lo que en verdad quiere es tomar, agarrar o golpear, ser tomado, agarrado o golpeado, pues su finalidad es evidente y no acepta mediación. En cuanto interpone una niebla de palabras (comunicación), miente; es que quiere satisfacerse sin peligro y sin riesgo. Ese riesgo no ha sido corrido muchas veces por Borges, quien sabe si por celos (los ha confesado), por desconfianza (es lo mismo) o por excesivo peso de una filosofía centrada en los griegos (la razón). Claro, que lo que la lucidez mortal de J.L.B. no permite, es la confusión entre el amor y la esclavitud (o el puchero y el colchón).

Repito, pues, que esa sería la lección de este Informe de Brodie. Escondida tras una ambigüedad: "Tenemos el deber de salvarlos" (a los Yahoos) reposa la ironía, porque ellos representan, como nosotros, la cultura y no somos superiores por asimilarlos. Si aplicamos puntualmente esto a las relaciones con el tú, posiblemente estemos por encima de esta Civilización pero, desde luego, sí estamos fuera del repaso que J.L.B. le da en este libro. Que Borges esté al margen de la cotidianidad es algo ya proverbial: "Quien recorre los diarios cada mañana lo hace para el olvido o para el diálogo casual de la tarde" 6 , pero esa economía no quiere decir sino lo contrario. Así puede tener el oído puesto a sus intereses, limpio de polvo y paja, para seleccionar las mejores historias, que refresquen sus temas. El es el intermediario: "No aspiro a ser Esopo". Se persuade el que quiere, el que no, podrá, al menos, distraerse hasta la noche 1.002. Así, bajo la solapa de tafetán del malabarista está escondida el arma del moralista.

Van sucediéndose los amables narradores que le descubren el asunto al avisado borges: Santiago Dabone, Santiago Fischbein, Emilio Trápeni, Carlos Reyles, etc., aunque hay dos relatos en los que el narrador no necesita

3. "Guayaquil" en El informe de Brodie, en ed. cit., pág. 711.

4. $\mathrm{M}^{\mathrm{a}}$. Esther Vázquez, Borges: Imágenes, memorias, diálogos, Monte Avila, Editores, Caracas, 1977, pág. 25.

5. "El informe de Brodie" en El informe de Brodie, ed. cit., pág. 717.

6. "El encuentro", ibíd., pág. 682. 
intermediarios, "La Señora Mayor" y "Guayaquil". En uno, no se sabe cómo Borges conoce la historia, en otro, él es el protagonista. ¿Qué mejor forma de presentar la Historia que diciendo "Se cuenta..."? En un relato en el que la Sra. Historia -Mayor ella- se va a convertir en protagonista, mejor será adoptar el modelo tradicional de los cuentos. Cuenta Alicia Jurado (otra incondicional borgiana) que, harta ya de las abundantes alegorías que los intelectuales encontraban en los cuentos de Borges, fue, perpleja, a preguntarle hasta qué punto se justificaban semejantes "descubrimientos". La respuesta fue clara: "Mis cuentos no son alegóricos ni encierran significados ocultos, deben ser satisfactorios en sí mismos, como juegos que son"”.

Si Borges, pues, aspira al juego y su lucidez le impide, claro, caer en certeza alguna, el que esto escribe no puede aspirar sino a que se le tome a juego y por éste continúo y así digo:

Que estos dos relatos en los que no hay intermediario, podían ser los antecedentes de esa excursión casi bíblica que a través de las pasiones y engaños van a ir vertebrando las hazañas de este libro. Quedará para el final el propio "Informe de Brodie" en el que Borges hace de traductor simplemente. Entre medio quedará, estirado, como el lomo del miedo, el desfile terco de la sinrazón. Por eso la "Sra. Mayor" y "Guayaquil" podían ser la Historia y la Voluntad. Desautorizada una y desamparados, pues, de toda asistencia y posibilidad de desagravio que la memoria de los hombres nos haga, ¿a dónde asirnos?. Sólo a la otra, la voluntad. Zimmermann sentenció: "Acaso las palabras que cambiaron fueron triviales. Dos hombres se enfrentaron en Guayaquil; si uno se impuso, fue por su mayor voluntad, no por juegos dialécticos. Como Vd. ve, no he olvidado a mi Schopenhauer"8.

Una vez derrocada la fe en la Ciencia Histórica y asegurado el puntal fundamental que sostiene nuestras vidas: la voluntad (recordemos la admiración de J.L.B. por El mundo como voluntad y representación, Borges podrá contarnos algunas conductas curiosas recogidas en el poso de su soledad voluntariosa. "¿Acaso no ha razonado Freud y no ha presentido W. Whitman que los hombres gozan de poca información respecto a los móviles profundos de su conducta?". Pues esos mismos móviles son los que va a ir reconstruyendo Borges, encarnados en los distintos relatos. Así, la culpa en "La intrusa", la venganza en "Juan Maraña", el odio de la guerra en "El Encuentro", el arte como pretexto de competitividad en "el Duelo", o la misma competitividad encarnizada en "El otro Duelo". La traición y la necesidad de contar la delación para calmar la culpa, en "El Indigno", por último, la manía de instaurar un orden, que siempre es precario y se apoya en la negación de los demás, en "Rosendo Juárez". No queda resquicio para el

7. Alicia Jurado. Genio y figura de J.L. Borges. Editorial Universitaria de Buenos Aires. Buenos Aires, 1964, pág. 113.

8. "Guayaquil", en El informe de Brodie, ed. cit., pág. 709. 
amor pero sí para el "Evangelio según San Marcos" y su moraleja: el creyente (otro móvil profundo), al jugar el papel de ingenua, parece en él.

El "Informe de Brodie", como algo fuera de estos mandamientos antibíblicos y, desde luego, tomado con la siempre-fina-ironía de Borges, sería, como dije, la lección: "Los Yahoos son un pueblo bárbaro, quizás el más bárbaro del orbe, pero sería una injusticia olvidar rasgos que los redimen". Salvarlos es dejarlos como son, respetarlos. Porque, ¿para qué les vamos a contar el decálogo anterior, nuestra Biblia de cada día?. Espero -acaba Borges el libro- que el Gobierno de Su Majestad no desoiga lo que se atreve a sugerir este Informe. Amar sin englobar, convivir sin poseer, ¿ha sido ése el límite y el dolor de J.L.B. como persona?.

Ya sólo me queda empezar por el comienzo. ¿Quién es la Historia en la "Sra. Mayor"?

\section{Dos Supuestos como prefacio a las Tablas de la Ley}

Si María Justina Rubio de Jáuregui "es archivo alocuente de cien años de la historia argentina", elocuente es por demás que no mane palabra ninguna mientras el Presidente, los ministros, las Damas de la Patria... le cantaban el Himno. El ruido (interferencias en la comunicación) de la turba, los fogonazos, el discurso y los uniformes, apresuraron su fin. Ella es la Historia real, pertenece a una familia honrosa y venida a menos, presidida por una sombra épica y por una hija que nació en el destierro. Abomina de los dictadores; los protestantes, judíos, masones y herejes son, para ella, palabras sinónimas sólo, y los españoles godos, como lo habían sido para sus padres. "Ya no sueño más que con muertos", fue una de las últimas cosas que le oyeron decir. Nunca fue tonta, pero no gozó mucho de placeres intelectuales (o sea, que no iba mucho más allá de los datos); le quedarían los de la memoria, y después el olvido. Hasta que se hundió en el entresueño, contaba sucedidos históricos, pero siempre con las mismas palabras y en el mismo orden.

Como la gente que figura, (ignoraban a ella y a su familia), la calle que les conmemora, que muy pocos conocen, estaba perdida en los fondos del cementerio del Oeste.

Taponada, pues, la única voz que podía aclarar los malentendidos del absurdo presente, hay que salvarse individualmente: " $\mathrm{AAh}$, Schopenhauer, que siempre descreyó de la historia...!". La voluntad está está en Guayaquil. Borges, resignado al fin a ser Borges, tiene la obligación de salvarse y así plasma su fuerza de decisión en un relato que es casi copia-homenaje de J. Conrad. En efecto, en Nostromo y casi con idénticas palabras, Conrad describe la geografía tropical de Costaguana y, aunque Borges suele decir de donde coge las citas o toma parodias, en este caso no lo hace. La voluntad, claro es, Zimmermann: "Nada singular había en él, contaría unos cuarenta años y era algo cabezón", aunque reconoce que Borges lleva la historia en la sangre, y le envidia, sentencia claramente: "Dos hombres...". Lo que 
cuenta es la voluntad. Borges siente pronto que nada le cuesta al alemán, darle la razón y adularle, dado que el éxito era suyo. Al salir, volvió a detenerse ante los tomos de Schopenhauer. Nuestro común amigo -le dice-conjeturaba que ningún acto es involuntario. Es por demás significativo el final de "Guayaquil", supone un suicidio literario: "Presiento que ya no escribiré más. Mon siège est fait". ¿Por qué sobreviene ese desánimo y qué es lo que le hace incumplir el presentimiento?:

\section{Los mandatos de la Biblia Cotidiana}

La escritura alucinante de Tlön -si hemos de dar crédito a las consultas de Borges sobre el volumen que registra la existencia de Orbis Tertius- establece una sola e incontrovertible pretensión, a saber: "El libro que no encierre su contralibro es considerado incompleto"

El contralibro que refleja los móviles desconocidos de la conducta de los hombres es el que va a tramar este catálogo. Estos mandamientos son los que producen la realidad y los que, desgraciadamente, y dada su avanzada edad, le han enseñado la resignación de ser Borges.

¿Quizás el presentimiento no se ha cumplido por el solo cometido de enviar este Informe Brodie a Su Majestad?. No lo creo. Está siempre el juego: fuerza motriz, desmadre de la vida. Y no olvidemos los mentideros: "De él se ha dicho a menudo no vacila en sacrificar a un amigo por una frase ingeniosa"10.

Vayamos, pues, con ese rastreo de la época humana en busca del contrahéroe que aparecería al revelar ese negativo particular de la Metafísica borgiana. No olvidemos que quizás su mejor definición sea la de "pensador místico".

\section{A) La culpa en la intrusa}

Para que una sociedad funcione tiene que aceptarse un código moral previo. El sometimiento de la libertad -que para Borges es el llano- a un articulado, supone una expiación, una culpa. Ya hay dos hermanos cuya unión inmaculada ha sido vertida a términos reales: "Caín andaba por ahí, pero el cariño de los Nilsen era muy grande". La sangre, el crimen se colocó en su lugar y, por tanto, pudo comenzar la Historia. Ya tenían el vínculo y una obligación, lenta pero ineludible: "olvidar a la mujer tristemente sacrificada". Tenía que ser la mujer, la manzana, no podía darse de otro modo. Con ese modo peculiar e inhumano, que Borges tiene, de codificar a la mujer en sus cuentos. No es que yo quiera contradecir a Ana $\mathrm{M}^{\mathrm{a}}$. Barrenechea, que se ha encargado de hacer notar que "en Borges falta totalmente

9. “Tlön, Uqbar, Orbis Tertius" en Ficciones, en ed. cit., pág. 260.

10. Entrevista con $\mathrm{M}^{\mathrm{a}}$. Esther Vázquez, en ed. cit., pág. 151. 
la idea de culpabilidad". Tampoco en este relato encontramos ningún juicio ético, explícito ni implícito. El escritor J.L.B. presenta sus pesonajes sin demostrar simpatía por ninguno ni preocuparse por el problema del bien y del mal. Lo que hace "La Intrusa", y aquí hago resaltar, es, simplemente, que Eduardo y Cristián se abrazaron, casi llorando. Les unía el crimen y la obligación de olvidar. No son buenos ni malos. Como todo ser humano tienden a olvidar lo desagradable y, desde luego, la intrusión del amor no les ha traído la felicidad. La Juliana ha sido la tentación y el error. Borges mata con la indiferencia a que nos tiene acostumbrados, de modo intelectual, Es un rasgo más de su "humour" británico, basado casi siempre en el "understatement".

\section{B) Lav venganza en Juan Maraña}

Tras el crimen encubierto -la hermandad de los hombres en la infamiaestá preparado el terreno de la venganza. Por alguna mano que no olvide llegará la expiación. Orestes vendrá agazapado y ha de ser la fuerza acumulada de Agamenón la que ejecute a Clitemnestra. La misma día Florentina, con la fuerza de Juan Maraña, la que pulverice al gringo Luchessi. El malevo tiene un arma escondida en el gesto, pero no nació con ella; es casi su misión en la Historia, los móviles de la Tragedia le empujan irreductibles. (Una visión pacata, recortada del hombre, hace que Alicia Jurado -incondicional ella- nunca entienda la atención de Borges hacia los malevos.) No se podía pintar mejor la figura de la venganza: "Vivía sola, ya entrada en años, algo rara. Flaca y huesuda, era, o me parecía, muy alta y gastaba pocas palabras... más de una vez la pesqué robando y escondiendo comida. En el barrio decían que la muerte, o la desaparición de Muraña la había trastornado. La recuerdo siempre de negro. Había dado en el hábito de hablar sola".

Al fin estaba mandaba por el odio, por la locura y tal vez, quién sabe, por el amor. Es el amor frustrado, de ciénaga maldita, que aparece en los cuentos de Borges pero al que muchos de sus personajes siguen adorando: La daga de Juan Maraña.

J.L.B. negando sus razones a A. Jurado sobre la simbología de sus cuentos, concluye éste diciendo: "en el arma de los hechos (de Juan Maraña), veo entrever un símbolo o muchos símbolos", y nos recuerda la distancia sideral de los símbolos y lo que nos espera: "fue un cuchillo y ahora la memoria de un cuchillo y mañana el olvido, el común olvido". Pero, mientras, se ha cumplido otro móvil, un placer de los dioses, la venganza, que bien pudiera quedar plasmada en ese sueño que Borges incluye en el relato: "La figura de Juan Maraña saco la mano y lo que ví fue una garra de buitre. Me desperté gritando en la oscuridad". 
Esa es la perspectiva desde la que J.L.B. enfoca la peripecia humana. Está por debajo de la Historia de los libros, es sin más, la ley de la selva: el buitre, el tigre y El Libro de los Seres Imaginarios. Curiosamente cuenta Borges en algún lado, cómo Margarita Guerrero, Bioy Casares y él quisieron hacer un recuento de especies fantásticas, recorrieron la $H^{a}$. Natural de Plinio, Las tentaciones de San Antonio de Flaubert, La Rama Dorada de Frazer, etc., y llegaron a la conclusión de que era mucho más fantástica la recopilación de las zoologías de animales reales. El paralelo con los hombres está el alcance. Sólo hace falta que una inteligencia ilumine las relaciones. Estamos en pleno bosque -animado- y "La Nature est un temple où de vivants piliers/Laissent parfois sortir de confuses paroles" 12 .

\section{C) La guerra: el encuentro}

Las armas se fabrican para dominar, para imponer la ley y para matar. Ellas representan el despegue del mono, el estadio del hombre. Aquella tarde de 1910 pelearon Maneco Uriarte y Duncan, Moreira y Juan Almada, Julio César y Marco Antonio... "me refirió su historia, siempre más o menos la misma, con diferencias de localidades y fechas". Cuando Maneco Uriarte mata a Duncan, solloza sin disimulo. Se arrepiente menos de su crimen que de la ejecución de un acto insensato. Es, simplemente, el odio de la especie, las claves que han quedado grabadas, durante los siglos, en el programador humano. Bien pensando sobrepasa la capacidad, no se explica desde el sentido. Los hombres no solían pelear, pelearon sólo las armas. La Destrucrión Nuclear sobreviene porque para eso están construidos los misiles; nc es necesario que los hombres lo entiendan, es ley histórica. Los datos son: lo para el diálogo casual de la siguiente tarde.

\section{D) El progreso de los "artistas": el duelo}

No todo el mundo tiene coraje y frontalidad como para luchar "a sangre y fuego" en sus duelos. El duelo existe en el texto, el arte puede ser la ocultación, el pre-texto, más abajo está el amor y su juego de posesiones. Hay un hombre: Dr. Figueroa, dos mujeres: Clara Glencairn y Nélida Sara. En el centro, como fuerza inductora e incitadora, otra mujer: Marta Pizarro. Borges avisa, antes de contar la historia: "los episodios importan menos que la situación que los causa, y los caracteres".

"La vida exige una pasión": Clara, quizás, demostrarse a sí misma y a su marido, que es digna del amor del Dr. Figueroa, Marta Pizarro, humillar a Clara, justificándose ayudándola y superándola. Nélida -quizás por encima de la pintura- enamorar al Dr. Figueroa.

El arte -según se entiende en la proyección social- puede no pasar de aquí, sin más trascendencia. La batalla incruenta, la historia que se mueve en la sombra y en ella acaba, se mantiene entre Marta y Clara. Al acabar una, desaparece la otra. Es el arte hecho contra alguien y que, en ningún

12. "Correspondances", en Spleen e Ideal. Ch. Baudelaire. Libros Río Nuevo, Barcelona, 1974, pág. 41. 
caso tiene como fundamento el crecimiento de la persona, sino la búsqueda del reconocimiento popular, la obtención de premios, la humillación del enemigo (del amigo). La vida exige una pasión, y ésta puede ser la pantomima artística, de este siglo y de todos.

\section{E) La sangre: El otro duelo}

"La falta de imaginación las libró del miedo y de la lástima". Esos dos fantasmas son, quizás, atributos muy afines a los artistas. Son proyecciones interiores de la falta de coraje, que sí tienen Silveira y Cardoso, que, quizás, no tenían para batirse a campo abierto, Clara Glencairn y Nélida Sara. El lienzo fue el tablero de ajedrez y en este cuento no fue posible la causalidad mágica de los dos reyes que pelean entre los escaques mientras sus ejércitos lo hacen abajo, en el llano, con las lanzas. Allí el duelo quedó entretenido en la imaginación, no llegó a calar a la sangre. Este es, exactamente, el otro duelo. A todas luces, auque fuera escasa la imaginación, siempre estaríamos por el primer duelo.

De nuevo Borges redunda, la historia no importa. El combate ocurrió en un lugar cuyo nombre nunca supieron. Los nombres los ponen después los historiadores.

$\mathrm{Ni}$ aquí, en duelo de la sangre, ni en el anterior, gana nadie. Los cuatro son víctimas de su obsesión y de su morbosa falta de aliento para entender y abrazar la vida con más perspectiva. Se justifican en una encrespada desazón de cloaca que va de sombra a sombra.

\section{F) El orden elegido por Rosendo Juarez}

¿Quedan otras actitudes que no sean duelos?. Por distintas sendas es posible el acomodo en la trastienda. El orden se cimenta sobre la historia, sobre el crimen. El deshonor y la fe, ciega siempre, son veredas que rehúyen el enfrentamiento y que se despliegan en otros tres relatos: $\mathrm{La}$ " $\mathrm{H}^{\mathrm{a}}$. de Rosendo, El Indigno y el Evangelio según San Marcos".

El orden es un paso adelante en el fondo de la selva. Es sólo una tregua, el refugio de una cobardía. Rosendo Juárez no tiene rubor en acatar su cobardía. Antes, solapado por el orden casi cometido por inercia, J.L.B. nos presenta el crimen de Rosendo Juárez como algo casi ineludible y trabado desde tiempo: "había visteado muchas veces conmigo y yo sentí que iba a churarme. Yo iba por la derecha del callejón y él iba por la izquierda: "Una vez calado el puñal, el orden lo asimila para las elecciones: "matón de comité".

Como el Lazarillo, sueña con establecerse en un barrio de orden. No tiene la organización social más misterio ni historia para Borges: Un crimen expiado, comités de matones, la cobardía, el olvido de San Telmo.

G) El deshonor del indigno.

El final de un relato de Octavio Paz, que no me paro a cotejar, acaba con una disyunción por demás explícita. Alguien comenta, ante un triste cuadro natural, la única salida en este mundo está entre el deshonor y el 
patíbulo. Esa -parece ser-fue la duda, quizás hasta el final, del difunto Santiago Fischbein, amigo de Borges y librero. No es de extrañar que el maestro tenga tales judíos por amigos. Así reza un poema de su último libro:

En la pública luz de las batallas

otros dan su vida a la patria

y los recuerda el mármol.

Yo he errado oscuro por ciudades que odio.

Le di otras cosas.

Abjuré de mi honor,

traicioné a quienes me creyeron su amigo, compré conciencias, abominé del nombre de la patria.

Me resigno a la infamia.

(El espía/del libro La Cifra $)^{13}$

Borges se resigna a la infamia y El Indigno tiene culpa, roe el remordimiento. Es curioso. El librero indigno también buscó, y alardea de su orden. También en este caso -querido Rosendo Juárez- hay crímenes bajo la capa espesa de la ley: "Yo -dice- tengo mi mujer y mis hijos, me he afiliado al partido socialista, soy un buen argentino y un buen judío. Soy un hombre considerado".

Bajo ese hombre de orden queda su autodesprecio. Su propio psicoanálisis hecho de 3 frases en el relato: "Yo sentía el desprecio de la gente y yo me despreciaba a mí mismo. Ojala me maten. Es lo mejor que puede pasarme. Era importante ser valiente, yo me sabía cobarde".

Ahora es cuando puede entenderse la ironía borgiana puesta en boca de Ferrari:

-“¿Usted me tiene fe?

-Sí -me contestó-. Sé que te portarías como un hombre".

Es, claro, otra cara del poliedro que compone el libro. Es la versión de estos hombres que buscan el refugio de la ley, vistos desde la sacristía de esa ceremonia de la confusión que, no en vano, define Borges -en este cuentocomo igual a la vida. J.L.B. sigue empeñado en enfocar al hombre desde una intimidad intolerable. La moraleja del cuento, que hace avanzar el relato, sería: Puesta la ley, llega el chivato.

\section{H) El creyente: El Evangelio según San Marcos}

Ferrari se equivocó al poner su fe en un cobarde. Ni él tenía nada que dar ni el indigno librero era tierra ingenua donde sembrar nada. Hace falta construir una personalidad como la de Baltasar Espinosa para hacer creíble en el lector esta verdad: El mensaje bíblico, vivido hasta sus últimas consecuencias, no es de este mundo. No cabe en él, y por tanto, cualquiera que

13. La Cifra, J.L. Borges, Alianza Editorial Tres, Madrid, 1981, pág. 85. 
lo encarne, se hará tan descomunal y extraño que, cualquier duda-que, por tanto, exige prueba- puede echarle abajo. El que cree es víctima pues de su propia fe. Pero, veamos, ¿cómo es la personalidad de Baltasar Espinosa?: "Una casi ilimitada bondad. No le gustaba discutir (quizás porque, en contraste con el hombre de hoy, tenía convicciones, no opiniones). Su abierta inteligencia era perezosa. Nunca quebró la promesa hecha a su madre: rezar. De natural, complaciente". Esa encarnación de Borges, última antes del Informe, no cabe en el tiempo. La misma bondad que inspira, provoca a sus fieles ávidos de saber límites. El hombre soporta poca cantidad de verdad, el engaño le constituye, $y$, en todo caso, tiene urgencia por conocer hasta dónde debe asimilar. El crimen les dará algún conocimiento: el de sí mismos, el de su propio patio interior; la historia y su cadena de confusiones. Es el fin y el principio, el broche del círculo. Así se clausura esta antibiblia borgiana. Queda el Informe.

\section{Petición hecha a S.M. la Reina}

Toda esa canalla es la que nosotros, los civilizados, queremos imponer a los Yohoos. Así se desvela, meridianamente, el final del libro.

Borges, que cuenta esa historia por boca de un misionero escocés, queda, también, al margen de esas palabras finales, pero el Informe es suficientemente hermoso como para que Borges poetice sus símbolos: "Al niño que ha nacido para rey lo mutilan, le queman los ojos, le cortan las manos y los pies, para que el mundo, no le distraiga de la sabiduría". "Venera, asimismo, a un dios cuyo nombre es Estiércol, y que posiblemente han ideado a imagen y semejanza del rey; es un ser mutilado, ciego, raquítico y de ilimitado poder. Suele asumir la forma de una hormiga o de una culebra".

Las sabidurías de los Yohoos son incontables, pero valgan dos muestras: Su infinito empieza en el pulgar y gozan de la facultad de previsión.

Son datos suficientes para declarar que hay que salvarlos. Todos menos enferularlos en nuestro código cotidiano. La experiencia, no obstante, viene a demostrar que hay pocas posibilidades de salvar lo diferente. Estos informes suelen quedar archivados o pasan a la hagiografía secreta de la Iglesia Católica.

Al fin y al cabo, esta es una petición a S.M. hecha por un poeta que tiene fama de chuflero y contradictorio. J.L.B. tiene el deber de iluminarnos.

Aquí habría, de nuevo, que retornar al comienzo. 
